\title{
Modification of milk fatty acid composition by feeding forages and agro-industrial byproducts from dry areas to Awassi sheep
}

\author{
S. Abbeddou, ${ }^{\star} †$ B. Rischkowsky, † E. K. Richter, ${ }^{\star}$ H. D. Hess, $\neq$ and M. Kreuzer ${ }^{\star 1}$ \\ ${ }^{*}$ ETH Zurich, Institute of Agricultural Sciences, Universitaetstrasse 2, 8092 Zurich, Switzerland \\ †International Center for Agricultural Research in the Dry Areas (ICARDA), PO Box 5466, Aleppo, Syria \\ $\ddagger$ Agroscope Liebefeld-Posieux Research Station ALP, PO Box 64, 1725 Posieux, Switzerland
}

\section{ABSTRACT}

The study tested the hypothesis that certain underused forages and agro-industrial byproducts available in dry areas may positively influence fatty acid (FA) composition and antioxidative properties of milk by their contents of residual oil or phenolic compounds or both. Sixty multiparous fat-tailed Awassi ewes were allocated to 6 groups in a completely randomized block design. During $50 \mathrm{~d}$, the ewes were group-fed $2.5 \mathrm{~kg}$ of dry matter/d per ewe 1 of 6 isonitrogenous and isoenergetic diets (forage:concentrate, 0.3:0.7). The test feeds, comprising $30 \%$ of the diets, replaced either barley straw [lentil straw, olive leaves, and Atriplex (saltbush) leaves, rich in phenolic compounds or electrolytes] or conventional concentrate ingredients (olive cake and tomato pomace; $\sim 10 \%$ lipids) from the control diet. The diets containing olive cake and tomato pomace were rich in oleic acid (18:1 cis-9; $27 \%$ of total dietary FA) and linoleic acid (18:2 cis-9,cis-12; 37\%), respectively. Profiles of FA were determined in individual milk samples drawn on d 0 and in wk 1, 3, 5 and 7. Data was analyzed by repeated measurement analysis. No consistent treatment effects on yield and gross nutrient composition of the milk were observed, although some differences occurred. Milk resulting from the Atriplex leaf diet expressed the highest antiradical activity, which was low with control and olive leaves. Feeding the tomato pomace and olive cake diets decreased the proportions of short- and medium-chain FA, whereas oleic acid clearly increased in proportion to total FA. Olive leaves most effectively increased rumenic acid (18:2 cis-9,trans-11) and $\alpha$-linolenic acid (18:3 cis-9, cis12,cis-15) in milk fat. This also resulted in the highest $\alpha$-linolenic acid transfer rate from feed to milk and suggests that olive leaves affect ruminal biohydrogenation at several steps. Several alternative feeds exist with an added value, as they enhance FA with potential health

Received January 7, 2011

Accepted April 17, 2011.

${ }^{1}$ Corresponding author: michael.kreuzer@inw.agrl.ethz.ch benefits and the stability of the milk with higher antioxidative activity, even though responses to test feeds differed largely. It remains to be investigated whether combinations of these feeds would be complementary in these beneficial effects.

Key words: forage, byproduct, fatty acid, Awassi

\section{INTRODUCTION}

Large sheep and goat populations and adverse climatic conditions cause feed shortages, thus limiting small ruminant productivity and farm income in the dry areas of the Mediterranean basin. The inclusion of underused shrubs and local agro-industrial byproducts in the diets, as alternatives to straw and cereal-based concentrates, is discussed as a potential solution (Vasta et al., 2008). However, such feeds often contain antinutritive compounds, which may decrease both their palatability and digestibility (Makkar, 2003a). A low nutritional value makes their use in high-yielding dairy cows inefficient (Chiofalo et al., 2004), whereas local breeds of dairy ewes have developed specific mechanisms for adaptation (Lanzani et al., 1993), allowing them to better cope with suboptimal diets. Research on alternative feeds is mostly restricted to the evaluation of their nutritional value and effects on animal performance. Only recently, some work has been conducted on changes in milk fatty acid (FA) composition when feeding olive cake (Chiofalo et al., 2004), olive leaves (Tsiplakou and Zervas, 2008) and tomato pomace (Romano et al., 2010), but this did not include a comparative evaluation of these feed alternatives.

Dietary FA composition determines the FA profile in milk; this even in ruminants, where the polyunsaturated FA (PUFA) are subjected to intensive microbial biohydrogenation, (Bauman and Griinari, 2003). The FA of interest for human health in the milk from ruminants include n-3 PUFA (Kromhout et al., 2010), among them $\alpha$-linolenic acid $[18: 3 \operatorname{cis}(\boldsymbol{c})-9, c 12, c 15]$. The $\mathrm{n}-3$ PUFA with more than 18 carbon atoms can be derived in man in small amounts from chain elongation and further desaturation of 18:3 $c 9, c 12, c 15$ (Burdge, 2006). Ruminal biohydrogenation of dietary PUFA also pro- 
duces nutritionally relevant FA (Chilliard et al., 2007). Here, the focus is on rumenic acid [18:2 $c 9, \operatorname{trans}(\boldsymbol{t})-11]$, a conjugated linoleic acid (CLA) isomer, and vaccenic acid (18:1 t11; Goudjil et al., 2004, 2007). The content of these FA in milk fat depends on the intake of their precursors and the degree to which the precursors are transformed during the ruminal biohydrogenation (Lourenço et al., 2008).

The composition of the diet can also influence the concentration of fat-soluble micronutrients in the milk, in particular $\beta$-carotene and $\alpha$-tocopherol (Martin et al., 2004), and plant secondary metabolites like phenolic compounds (O'Connell and Fox, 2001). These compounds are involved in the prevention of the photooxidation of the milk fat globule membrane, the major site of auto-oxidation (Lindmark-Månsson and Åkesson, 2000; O'Connell and Fox, 2001). The occurrence of these active principles in milk can also increase its nutritional and organoleptic quality (O'Connell and Fox, 2001; Nozière et al., 2006).

The present study tested the hypothesis that, in response to their particular composition, certain agroindustrial byproducts and forages may influence milk fat properties in a favorable way. Test feeds included tomato pomace and olive cake, both rich in lipids, olive leaves and lentil straw, both rich in polyphenols, and the salty leaves of the Atriplex bush. The feeds were obtained from a typical Mediterranean production area in Syria and their palatability, digestibility, and energy content has been determined in earlier experiments (Abbeddou et al., 2011a,b). In the current study, ewes of the Awassi breed, a fat-tailed dairy genotype adapted to the specific feeding and environmental conditions, were fed a diet that contained $30 \%$ of the test feeds. A special emphasis was put on the milk FA profile, FA transfer from feed to milk, and the antioxidant status of the milk.

\section{MATERIALS AND METHODS}

\section{Experimental Design}

The experiment was conducted at the International Center of Agricultural Research in the Dry Areas (ICARDA, Aleppo, Syria). Sixty Awassi ewes in their second to fourth lactation, weighing, on average, 51.0 $\pm 6.8 \mathrm{~kg}$ were kept indoors and allocated to 6 dietary treatment groups in a completely randomized block design. At the start of the experiment, the sheep were $67.2 \pm 10.0$ DIM, after the lambs had been allowed to suckle for $2 \mathrm{mo}$, consistent with common practice in Syria. Additionally to these 2 criteria, the groups were also balanced for individual milk yield, as well as milk fat and milk protein contents.

\section{Diets and Feeding}

Three forages and 2 agro-industrial byproducts were tested in comparison with a barley-straw concentratebased control diet, which consisted of ingredients traditionally used in Syria. Lentil (Lens culinaris) straw was purchased from a market in Aleppo. Fresh branches from saltbush (Atriplex halimus) were collected from the steppe in the Adameh area. Olive (Olea europea L.) branches from routine pruning of the trees were purchased on the Afrin market in Aleppo. The tomato pomace originated from the tomato purée factory Conserva (Edleb, Syria). The residue from the first press of green olives, which included peel and kernels, was obtained from a traditional cold pressing olive oil factory in Afrin. The fresh leaves and tomato pomace were immediately sun-dried for 3 to $4 \mathrm{~d}$, whereas olive cake was oven-dried at $40^{\circ} \mathrm{C}$ for $4 \mathrm{~d}$ at ICARDA's facilities. Afterward, leaves with small twigs of olive and Atriplex were separated by hand from larger branches. All feeds had been obtained as batches for the entire experiment and batches were the same as those that had been evaluated in earlier experiments (see more details in Abbeddou et al., 2011a,b).

All test feeds constituted $30 \%$ of DM of the complete diets (Table 1). Diets were balanced for their contents of energy as measured previously (Abbeddou et al., 2011a,b) and CP. For the latter purpose, some urea was added to the concentrates. Diets were composed of forage and concentrate in a ratio of 30:70, except for the olive cake diet with a ratio of 20:80. Barley straw, as the control forage, was completely substituted by lentil straw, Atriplex, or olive leaves in the respective diets. Proportionately, $3 / 7$ of the control concentrate, mainly consisting of sugar beet pulp, wheat bran, and cottonseed meal, was replaced by olive cake or tomato pomace. The limited energy content of these feeds required that also wheat grain was used to replace wheat bran and all or most of the sugar beet pulp. Molasses was added to all diets to improve palatability (mixed with olive leaves, Atriplex leaves, and the concentrate for the other diets). All groups received $20 \mathrm{~g} / \mathrm{d}$ per head of a vitamin-mineral mix which was mixed with the concentrate. Diets containing tomato pomace and olive cake were rich in lipids (ether extract and total FA) compared with the other diets (Table 2). The lipids of the control diet were characterized by high proportions of saturated FA, followed by linoleic acid (18:2 $c 9, c 12$; $\mathrm{n}-6)$. Linoleic acid was the main FA in the tomato pomace and lentil straw diets, and the PUFA proportion was high. In olive cake, oleic acid (18:1 $c 9$; n-9) was particularly prominent, resulting in an equal proportion of 18:1 $c 9$ and 18:2 $c 9, c 12$ in the olive cake diet, where these 2 FA represented more than half of the total FA. 
Table 1. Ingredients of the experimental diets $(\% \text { of DM })^{1}$

\begin{tabular}{lcccccc}
\hline & \multicolumn{7}{c}{ Experimental diet } \\
\cline { 2 - 7 } & Control & $\begin{array}{c}\text { Lentil } \\
\text { straw }\end{array}$ & $\begin{array}{c}\text { Atriplex } \\
\text { leaves }\end{array}$ & $\begin{array}{c}\text { Olive } \\
\text { leaves }\end{array}$ & $\begin{array}{c}\text { Olive } \\
\text { cake }\end{array}$ & $\begin{array}{c}\text { Tomato } \\
\text { pomace }\end{array}$ \\
\hline Test feed & - & 30 & 30 & 30 & 30 & 30 \\
Barley straw & 30 & - & - & - & 20 & 30 \\
Wheat grain & - & - & - & - & 30 & 20 \\
Sugar beet pulp & 30 & 20 & 30 & 30 & - & 5 \\
Wheat bran & 10 & 20 & 20 & 20 & - & 5 \\
Cottonseed meal & 20 & 20 & 10 & 10 & 10 & 10 \\
Molasses & 10 & 10 & 10 & 10 & 10 & \\
\hline
\end{tabular}

${ }^{1}$ Diets were individually supplemented with $20 \mathrm{~g}$ of mineral-vitamin mix/d per head, containing per kilogram: Ca, 138 g; P, 108 g; Mg, 151 mg; Na, 123.5 g; Cu, 119 mg; Mn, 774 mg; I, 76 mg; vitamin A, 12,500,000 IU; vitamin $\mathrm{D}_{3}, 300,000 \mathrm{IU}$; vitamin E, $0.5 \mathrm{~g}$; and urea at levels of $8,0,5,12,19$, and $16 \mathrm{~g} / \mathrm{kg}$ of DM for control, lentil straw, Atriplex leaves, olive leaves, olive cake, and tomato pomace diets, respectively.

At much lower total fat content, the olive leaf diet was especially rich in 18:3 $c 9, c 12, c 15$. This diet was richer in total phenols and total tannins than the other diets, followed by the lentil straw diet. The tomato pomace and olive cake diets were rich in lignified fiber, whereas fiber content was low in the Atriplex leaf diet.

Before the experiment started, the ewes had been fed $1.3 \mathrm{~kg}$ of $\mathrm{DM} /$ head of a mixed concentrate (barley grain, cottonseed meal and sugar beet pulp, 50:25:25) and grazed natural pasture at an approximate biomass intake of $0.7 \mathrm{~kg}$ of $\mathrm{DM} / \mathrm{d}$ per head. On experimental d 0 and 1,50 and $75 \%$ of this concentrate was replaced by the experimental concentrates and grazing was omitted. At the same time, barley straw and the other experimental forages (1:1) were offered in replacement of the pasture grass. From d 2 onwards, the ewes were exclusively fed the experimental diets, which were offered at increasing levels until reaching $2.5 \mathrm{~kg}$ of DM/d per head after $10 \mathrm{~d}$. These $10 \mathrm{~d}$ were part of the entire $50 \mathrm{~d}$ of the experiment. Eventually, per group, $0.75 \mathrm{~kg}$ of forage and $1.75 \mathrm{~kg}$ of concentrate per head per day were offered, except for the olive cake group, in which $0.5 \mathrm{~kg}$ of forage and $2.0 \mathrm{~kg}$ of concentrate were offered per head per day to achieve that this diet was also isoenergetic to the other diets. Half of the daily portions were provided at 0800 and $1700 \mathrm{~h}$ always directly after milking. Water was offered ad libitum.

\section{Data Recording and Sample Collection}

Samples of the dietary ingredients were drawn for analysis 3 times during the experiment. Body weight was measured at the beginning of the experiment and then every second week using a balance with 1-kg increments. This was done after milking and before feeding. Milking was performed daily starting at 0600 and 1600 $\mathrm{h}$ by a machine milking system; however, for the weekly recordings of daily milk yield and for milk sampling, milking was done manually, starting at the same time as machine milking. The weekly collected morning milk samples were immediately subjected to constituent composition analysis. Additional samples obtained on d 0 and wk 1, 3, 5, and 7 of the experiment were immediately stored at $-20^{\circ} \mathrm{C}$ for analysis of anti-radical activity and FA profile.

All procedures involving the animals followed the international guiding principles listed by the Council for International Organizations of Medical Sciences (2010).

\section{Gross Nutrient Analysis in Feeds and Milk}

Feeds were analyzed for their proximate contents by standard methods (AOAC, 1997). These included DM and total ash (AOAC index no. 942.05), CP (AOAC 977.02; using Kjeldahl unit Vapodest 30; C. Gerhardt GmbH \& Co. KG, Königswinter, Germany), and ether extract (EE; AOAC 963.15; Soxtherm Variostat; C. Gerhardt Ltd., Northamptonshire, UK). Contents of $\mathrm{NDF}, \mathrm{ADF}$, and acid detergent lignin were determined in feeds corrected for ash content. In the case of NDF, $\alpha$-amylase and sodium sulfite were used (Van Soest et al., 1991). Nonfiber carbohydrates were calculated as $\mathrm{OM}-(\mathrm{NDF}+\mathrm{CP}+\mathrm{EE})$. Additionally, total phenol and total tannin (Folin-Ciocalteu method; Makkar, 2003b), as well as condensed tannin, contents (Porter et al., 1986) were determined. Total phenol and total tannin contents were expressed as tannic acid equivalents and condensed tannins as leucocyanidin equivalents.

Contents of fat, protein, lactose, TS, and SNF in milk were measured by the Milkoscan 133 B (Foss Electric, Hillerød, Denmark). The ECM (kg/d) was calculated based on the ALP (2008) formula as milk $(\mathrm{kg} / \mathrm{d}) \times$ $[0.38 \times$ fat $(\%)+0.24 \times$ protein $(\%)+0.17 \times$ lactose $(\%)] / 3.14$.

\section{Analysis of the Antiradical Activity of the Milk}

The antiradical effect of individual milk samples on the free radical 2,2-diphenyl-1-picrylhydrazyl (DPPH) 
Table 2. Nutrient composition $(\%$ of $\mathrm{DM})$ of the different experimental feeds and diets as offered $(\mathrm{n}=3)$

\begin{tabular}{|c|c|c|c|c|c|c|c|c|c|c|c|}
\hline \multirow[b]{2}{*}{ Item $^{1}$} & \multirow[b]{2}{*}{ Control } & \multicolumn{2}{|c|}{ Lentil straw } & \multicolumn{2}{|c|}{ Atriplex leaves } & \multicolumn{2}{|c|}{ Olive leaves } & \multicolumn{2}{|c|}{ Olive cake } & \multicolumn{2}{|c|}{ Tomato pomace } \\
\hline & & Feed & Diet & Feed & Diet & Feed & Diet & Feed & Diet & Feed & Diet \\
\hline $\mathrm{OM}$ & 89.7 & 89.0 & 89.6 & 69.0 & 83.4 & 91.1 & 89.3 & 86.4 & 87.5 & 95.2 & 89.8 \\
\hline $\mathrm{CP}$ & 17.4 & 9.3 & 17.6 & 16.1 & 17.6 & 9.4 & 17.5 & 7.9 & 18.4 & 19.1 & 18.1 \\
\hline NDF & 41.5 & 42.7 & 32.1 & 25.8 & 29.3 & 27.8 & 29.7 & 58.4 & 42.8 & 55.2 & 46.3 \\
\hline $\mathrm{ADF}$ & 24.3 & 30.5 & 21.4 & 16.5 & 18.1 & 22.8 & 19.8 & 45.9 & 23.4 & 46.2 & 27.1 \\
\hline ADL & 3.88 & 7.27 & 4.79 & 7.93 & 4.68 & 10.94 & 5.53 & 23.74 & 8.64 & 25.9 & 9.47 \\
\hline Non-NDF carbohydrates & 32.0 & 32.7 & 37.5 & 25.1 & 36.4 & 44.4 & 41.9 & 10.9 & 28.6 & 10.9 & 26.6 \\
\hline Ether extract & 1.04 & 1.49 & 1.52 & 1.40 & 1.33 & 3.15 & 1.84 & 9.22 & 3.07 & 9.99 & 3.34 \\
\hline Total FA & 1.97 & 0.78 & 2.49 & 0.48 & 1.80 & 0.78 & 1.87 & 5.91 & 2.98 & 13.36 & 4.74 \\
\hline \multicolumn{12}{|l|}{ FA ( $\%$ of total FAME) } \\
\hline $16: 0$ & 25.5 & 19.8 & 19.8 & 28.6 & 22.9 & 24.7 & 21.6 & 17.5 & 19.2 & 14.5 & 20.5 \\
\hline $16: 1$ & 0.67 & 0.26 & 0.50 & 0.38 & 0.60 & 0.46 & 0.62 & 0.59 & 0.39 & 0.33 & 0.38 \\
\hline $18: 0$ & 2.63 & 4.83 & 2.57 & 3.27 & 2.02 & 2.62 & 1.81 & 4.98 & 2.97 & 4.59 & 3.22 \\
\hline $18: 1 c 9$ & 14.2 & 11.5 & 15.2 & 10.0 & 14.6 & 12.7 & 15.3 & 64.2 & 27.0 & 20.7 & 13.7 \\
\hline $18: 2 c 9, c 12$ & 29.8 & 27.9 & 35.1 & 15.4 & 29.3 & 11.1 & 27.8 & 6.6 & 27.0 & 55.1 & 36.5 \\
\hline $18: 3 c 9, c 12, c 15$ & 2.4 & 11.6 & 4.9 & 14.4 & 6.0 & 25.7 & 9.3 & 0.3 & 2.0 & 2.6 & 2.8 \\
\hline SFA & 39.2 & 41.5 & 30.0 & 53.0 & 34.6 & 40.2 & 30.6 & 25.2 & 28.6 & 20.4 & 32.6 \\
\hline MUFA & 16.9 & 18.3 & 18.9 & 15.6 & 18.3 & 22.3 & 20.1 & 67.7 & 29.8 & 21.8 & 15.9 \\
\hline PUFA & 32.5 & 40.2 & 40.4 & 31.4 & 36.0 & 37.5 & 37.5 & 7.1 & 29.2 & 57.7 & 39.4 \\
\hline Total phenols ${ }^{2}$ & 0.67 & 2.80 & 1.32 & 0.63 & 0.57 & 6.35 & 2.25 & 0.41 & 0.53 & 0.64 & 0.60 \\
\hline Total tannins ${ }^{2}$ & 0.37 & 1.94 & 0.84 & 0.32 & 0.28 & 3.16 & 1.12 & 0.17 & 0.25 & 0.40 & 0.31 \\
\hline Condensed tannins ${ }^{3}$ & 0.10 & 0.44 & 0.22 & 0.00 & 0.05 & 0.05 & 0.07 & 0.00 & 0.05 & 0.00 & 0.04 \\
\hline
\end{tabular}

${ }^{1} \mathrm{ADL}=$ acid detergent lignin; FA $=$ fatty acids; FAME $=$ FA methyl esters; $c=$ cis; SFA = saturated FA; MUFA = monounsaturated FA; PUFA $=$ polyunsaturated FA.

${ }^{2}$ Tannic acid equivalents.

${ }^{3}$ Leukocyanidin equivalents. 
was measured using a slightly modified version of the protocol of Liu et al. (2005). Briefly, $75 \mu \mathrm{L}$ of the thawed milk was added to $1,425 \mu \mathrm{L}$ of DPPH solution $\left(6 \times 10^{-5}\right.$ $M$ dissolved in methanol), vortexed, and stored in the dark for $30 \mathrm{~min}$. Then the absorbance at $515 \mathrm{~nm}$ was measured using a UV-Vis spectrophotometer (model U-2000; Hitachi, Tokyo, Japan). Methanol was used for determining the baseline value. The absorbance of the DPPH radical without sample was used as a control. The antiradical activity is defined as the ability of the milk to scavenge DPPH free radicals, given in percent and calculated as (1 - absorbance of the sample at 515 $\mathrm{nm} /$ absorbance of the control at $515 \mathrm{~nm}) \times 100$.

\section{Fatty Acid Analysis}

Lipid extraction from the milled feed samples was done using a hexane-isopropanol solution (3:2). Amounts of 2 to $2.5 \mathrm{~g}$ were weighed into extraction thimbles and lipids were extracted overnight in an accelerated solvent extractor (ASE200; Dionex Corp., Sunnyvale, CA). As an internal standard, 11:0 (triglyceride, Fluka; Sigma-Aldrich Chemie GmbH, Buchs, Switzerland) was added. The solvent was then evaporated under an $\mathrm{N}_{2}$ stream with a TurboVap LV Evaporator (Zymark Center, Hopkinton, MA). Residues were dissolved in dichloromethane and evaporation under $\mathrm{N}_{2}$ was repeated. Conversion of FA to FA methyl esters (FAME) was carried out according to method 2.301 of IUPAC (1987) with slight modification. The extract was boiled with $2 \mathrm{~mL}$ of $\mathrm{NaOH}(0.5 M)$ for $3 \mathrm{~min}$, before $3 \mathrm{~mL}$ of methanolic boron trifluoride $(1.3 M)$ was added. The mixture was heated again for $4 \mathrm{~min}$ and the reaction was terminated by adding $7 \mathrm{~mL}$ of $\mathrm{NaCl}(0.34 M)$ and $1 \mathrm{~mL}$ of hexane. Tubes were shaken for $30 \mathrm{~s}$ and centrifuged at $894 \times g$ for $6 \mathrm{~min}$. Subsequently, $0.5 \mathrm{~mL}$ of the upper phase was purified on a column filled with silica gel (Merck KGaA, Darmstadt, Germany). The FAME were eluted with $6.5 \mathrm{~mL}$ of dichloromethane. These residues were injected into a gas chromatograph (HP 6890; Hewlett-Packard, Wilmington, PA) equipped with a Supelcowax-10 column $(30 \mathrm{~m} \times 0.32 \mathrm{~mm} \times 0.25$ $\mu \mathrm{m}$; Supelco Inc., Bellefonte, PA). Amounts of $1 \mu \mathrm{L}$ were applied by split injection (1:30) at an injection temperature of $260^{\circ} \mathrm{C}$. The carrier gas was $\mathrm{H}_{2}$, flow rate was $2.2 \mathrm{~mL} / \mathrm{min}$, and pressure was $55.8 \mathrm{kPa}$. The following temperature program was used: start at $160^{\circ} \mathrm{C}$ for $0.5 \mathrm{~min}$; increase by $20^{\circ} \mathrm{C} / \mathrm{min}$ up to $190^{\circ} \mathrm{C}$; increase by $7^{\circ} \mathrm{C} / \mathrm{min}$ up to $230^{\circ} \mathrm{C}$; isotherm at $230^{\circ} \mathrm{C}$ for $5.3 \mathrm{~min}$; increase by $20^{\circ} \mathrm{C} / \mathrm{min}$ up to $250^{\circ} \mathrm{C}$; isotherm for $6 \mathrm{~min}$. Fatty acids were identified and quantified with the HP ChemStation software (Hewlett-Packard, Wilmington, $\mathrm{NC}$ ), by comparison with other chromatograms, run under the same conditions (Collomb and Bühler, 2000) and with reference to an external FAME standard (Supelco 37 component FAME mix; Supelco Inc.). The FAME proportions were adjusted by the response factors of the FAME standard and the internal standard (11:0), and their quantity in feed was calculated based on the internal standard and the feed sample weight.

Milk samples were thawed in a water bath at $37^{\circ} \mathrm{C}$ and gently mixed to homogenously distribute the milk fat. The FA were extracted and analyzed according to the slightly modified method of Molkentin and Precht (2000). Briefly, $1 \mathrm{~mL}$ of milk was mixed with $2 \mathrm{~mL}$ of methanol and $1 \mathrm{~mL}$ of chloroform and then vortexed for $1 \mathrm{~min}$. Another milliliter of chloroform and $1 \mathrm{~mL}$ of distilled water were added to the tube and vortexed again for better phase separation. The lower phase was carefully extracted and evaporated under $\mathrm{N}_{2}$. Hexane (1 $\mathrm{mL}$ ) was added to the vial, which was then mixed with $20 \mu \mathrm{L}$ of sodium methylate solution (2 $M$ in methanol), shaken vigorously for $3 \mathrm{~min}$, and centrifuged at $493 \times$ $g$ (Kubota 3110; Kubota Corp., Tokyo, Japan) for 1 min. Thereafter, $100 \mathrm{mg}$ of sodium hydrogen sulfatemonohydrate was added and the vial was recapped, vortexed again for $2 \mathrm{~min}$, and centrifuged at $493 \times$ $g$ for $1 \mathrm{~min}$. One microliter of the clear supernatant was manually injected into the gas chromatograph (GC 2010; Shimadzu Corp., Kyoto, Japan) equipped with a highly polar (90\% biscyanopropyl/10\% phenyl cyanopropyl polysiloxane) capillary column (105 m × $0.25 \mathrm{~mm}$ i.d., 0.20- $\mu \mathrm{m}$ film, Rtx-2330; Supelco Inc.), a split-injection port and flame-ionization detector. Injector and detector temperatures were maintained at $250^{\circ} \mathrm{C}$. As carrier gas, helium was used with a flow rate of $1.30 \mathrm{~mL} / \mathrm{min}$ (linear velocity control). The initial oven temperature was set to $50^{\circ} \mathrm{C}$ for $3 \mathrm{~min}$. and then the following temperature program was used: increase by $5^{\circ} \mathrm{C} / \mathrm{min}$ up to $140^{\circ} \mathrm{C}$; isotherm for $2 \mathrm{~min}$; increase by $2^{\circ} \mathrm{C} / \mathrm{min}$ up to $170^{\circ} \mathrm{C}$; isotherm for $5 \mathrm{~min}$; increase by $10^{\circ} \mathrm{C} / \mathrm{min}$ up to $220^{\circ} \mathrm{C}$; isotherm for $5 \mathrm{~min}$; increase by $5^{\circ} \mathrm{C} / \mathrm{min}$ up to $225^{\circ} \mathrm{C}$; isotherm at $225^{\circ} \mathrm{C}$ for $20 \mathrm{~min}$. Fatty acids were identified and quantified with the GC Solution program version 2.3 (Shimadzu Corp.) and by comparison with other chromatograms obtained under similar conditions (Collomb and Bühler, 2000). The response factor of the FAME standard was used to correct FAME proportions. Their quantity in the milk fat was calculated based on the fat content of the milk. Total 18:1 cis was calculated as the sum of $18: 1 c 9, c 11$, $c 12$, $c 13$, and $c 14$; total 18:1 trans was the sum of 18:1 $t 4$ to $t 12$, and total CLA was the sum of $18: 2 c 9, t 11$, $c 9 c 11$, and $t 9 t 11$.

\section{Statistical Analysis}

Data were analyzed performing repeated measurement analysis using the MIXED procedure of SAS 
(version 9.2; SAS Institute, 2009) and assuming a compound symmetric structure. Effects considered were diet, week, and the interaction between the 2 factors, as well as the initial records measured at d 0 (covariate). The least squares means were statistically compared with the Tukey method both for diet and week. The same model was used for Figures 1 and 2, except that the initial records at $\mathrm{d} 0$ were not used as a covariate.

\section{RESULTS}

\section{Performance}

Feed intake was similar among the different test diets and the control diet, and almost no refusals were recorded. On average, ewes of all groups gained weight during the experiment. The ADG (g) were high with control and lentil straw (257), followed by Atriplex (235), with the diets containing tomato pomace, olive leaves and olive cake being lowest $(193,180$, and 175 , respectively; treatment effect, $P=0.037)$. Milk yield, expressed as ECM, was highest with the control diet and lowest with olive leaves $(P=0.005$; Table 3$)$, whereas the other diets did not cause milk yield to differ significantly from either the control or the olive leaf diet.

\section{Gross Nutrient Composition of Milk}

The milk fat content was unaffected by diet except for the lentil straw diet where it was $9.0 \%$ lower compared with the control $(P=0.029)$ and the olive cake diet $(P$ $=0.023$; Table 3 ). The milk total protein content was high with lentil straw and low with tomato pomace $(P$ $=0.003)$. The lactose content was highest with olive cake and lowest with the olive leaf and the control diet $(P<0.001)$. The diet type did not influence TS content, which first increased to reach the maximum from wk 3 to 4 and then decreased $(P<0.001)$ with progressing lactation (data not shown). The SNF contents were high with Atriplex leaves and lentil straw and low with tomato pomace $(P<0.01)$. No interaction between diet and week was observed for any compositional variable.

\section{Antiradical Activity}

Antiradical activity was highest in the Atriplex leaf diet (1.2-fold of the control antiradical activity) and lowest (0.95-fold of control) with the milk produced from the olive leaf $\operatorname{diet}(P<0.001$; Table 3$)$.

\section{Fatty Acid Composition of the Milk Fat}

The diets containing olive cake and tomato pomace led to clearly lower 16:0 and higher 18:0 proportions in milk fat compared with all other diets $(P<0.001$; Table 4). Compared with the control, the proportion of 18:0 was lower with Atriplex leaves $(P=0.018)$ and especially with olive leaves $(P<0.001)$. The same effect as for 18:0 was observed for 18:1 $c 9(P=0.013)$ and total 18:1 cis $(P=0.031)$ with the olive leaf diet. Total 18:1 trans FA proportions, including 18:1 t10 and 18:1 $t 11$, were enhanced by lentil straw and olive leaves. The proportion of 18:2 $c 9, c 12$ did not significantly differ among the test forages and control diet, but decreased $(P<0.001)$ with tomato pomace and olive cake. The total CLA proportions were highest $(P<0.001)$ in milk fat from the olive leaf and the tomato pomace diets, low with olive cake and control diets, and intermediate with lentil straw and Atriplex leaves. This was the same for the most prevalent CLA isomer, 18:2 $c 9, t 11$, but not for 18:2 $c 9, c 11$ and 18:2 t9,t11 (not displayed in Table 4). Compared with the control, the olive leaf diet promoted 18:3 $c 9, c 12, c 15$ to an almost 3-fold level, and proportions were also high with this diet for the longchain n-3 PUFA; 20:5 $c 5, c 8, c 11, c 14, c 17$ (2.1-fold of the control); 22:5 $c 7, c 10, c 13, c 16, c 19$ (1.4-fold of control); and 22:6 $c 4, c 7, c 10, c 13, c 16, c 19$ (1.3-fold of the control). Next to the olive leaf diet, diets with lentil straw and Atriplex leaves promoted a higher proportion of the n-3 FA compared with the control (mostly significant). The n-6:n-3 FA ratio was lower $(P<0.001)$ with olive leaves than with tomato pomace and the control, with the other dietary treatments being intermediate. The olive leaf diet also increased $(P=0.019)$ the proportion of the short-chain FA (SCFA, 4:0 to 11:0) compared with the control. The proportion of medium-chain FA (MCFA; 12:0 to 16:1) was similar for the control, olive leaf, and Atriplex leaf diets and lower $(P<0.001)$ with tomato pomace and olive cake. The latter diets, at the same time, increased $(P<0.001)$ monounsaturated FA proportions at a cost of the saturated FA. The proportion of the PUFA was low with olive cake $(P<0.001)$ and high with olive leaves and lentil straw $(P<0.001$ compared with the control). The statistical analysis showed an effect of the experimental week $(P<0.001)$ on most of the milk FA.

\section{Fatty Acid Excretion with Milk}

The daily excretion of the main PUFA and those FA, which are, at least partly, the result of their biohydrogenation, were mostly adapted to the new levels after 1 or 3 wk of experimental feeding (Figures 1 and 2 ). Thereafter, changes with time were small except for the two 18:1 trans FA ( $t 10$ and $t 11$ ) displayed. As effects of the diets on milk fat yield were not very large, excretion of individual FA was similarly affected by the experimental diets as the proportions of these FA of 

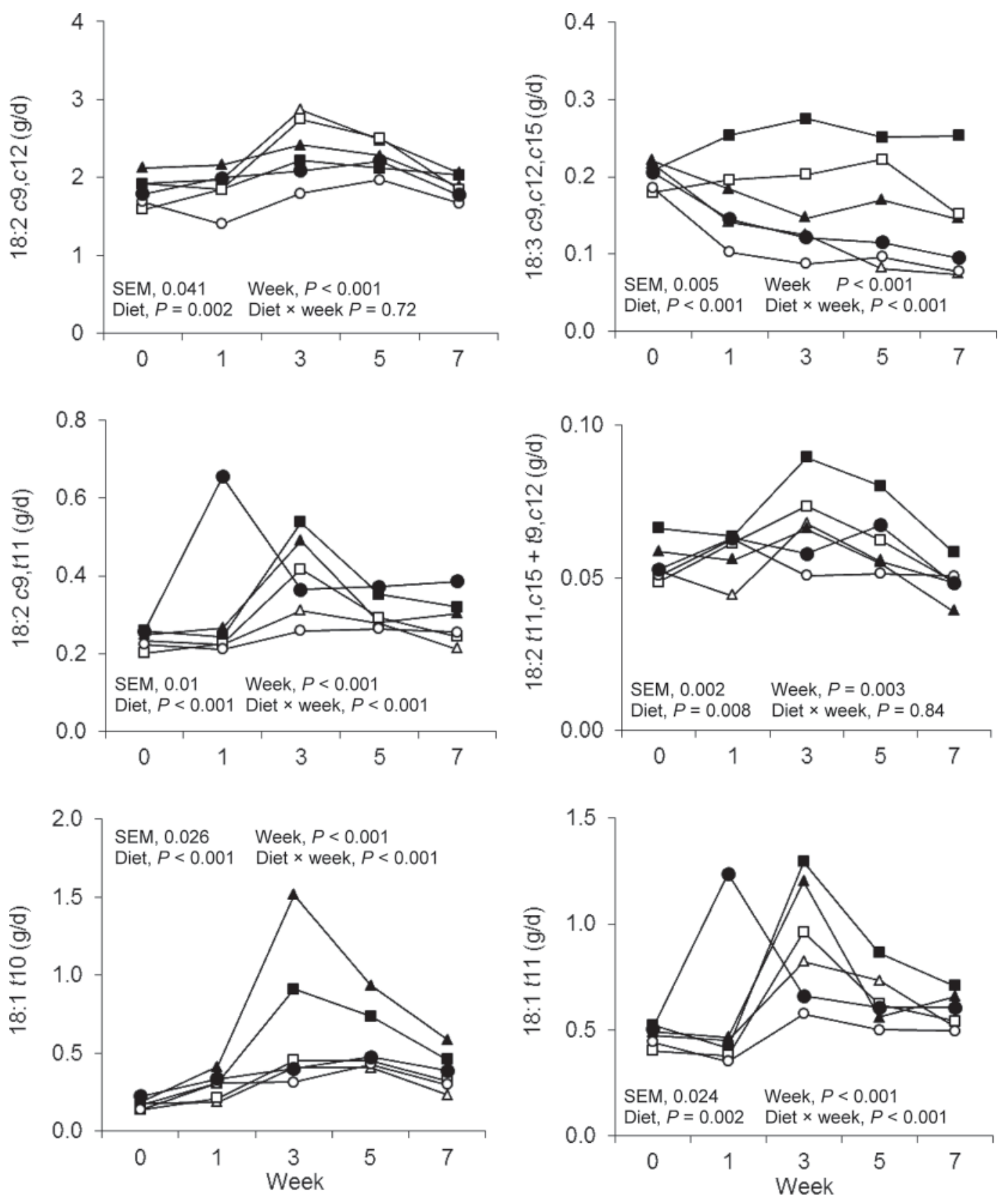

Figure 1. Evolution of the daily excretion of the 2 major polyunsaturated fatty acids [linoleic acid $(18: 2 c 9, c 12 ; \mathrm{n}-6)$ and $\alpha$-linolenic acid $(18: 3 c 9, c 12, c 15)]$ and their most important biohydrogenation products with the milk as affected by diet. $\Delta$, control; $\mathbf{\Delta}$, lentil straw; $\square$, Atriplex leaves; olive leaves; $\bigcirc$, olive cake; $\bullet$, tomato pomace. $c=$ cis; $t=$ trans.

total FAME. Diet differences were especially obvious for 18:3 $c 9, c 12, c 15$ (high with the olive leaf and Atriplex leaf diets), 18:1 c11 (high with the olive leaf diet), and 18:1 $c 9$ and 18:0 (both high with the olive cake and tomato pomace diets; Figures 1 and 2).

\section{Fatty Acid Recovery Rates}

When compared with their ingested amounts, the dietary FA, which are subject to modification by ruminal biohydrogenation $(18: 3 c 9, c 12, c 15,18: 2 c 9, c 12$ and 18:1 c9) were largely disappearing from feed to milk, whereas the terminal end product of biohydrogenation, 18:0, increased to levels that were 1.8- to 4.7-fold of those ingested (Table 5). Recoveries of 18:3 $c 9, c 12, c 15 ; 18: 2$ $c 9, c 12$; and the increase in 18:0 were small with tomato pomace and large with the control and Atriplex leaf diets $(P<0.001)$. Even though the olive cake diet was rich in 18:1 $c 9$ (27.0\% of total dietary FAME), which was well reflected in the milk fat $(20.4 \%)$, the recovery rate of 18:1 $c 9$ was lowest with this $\operatorname{diet}(P<0.001)$. 

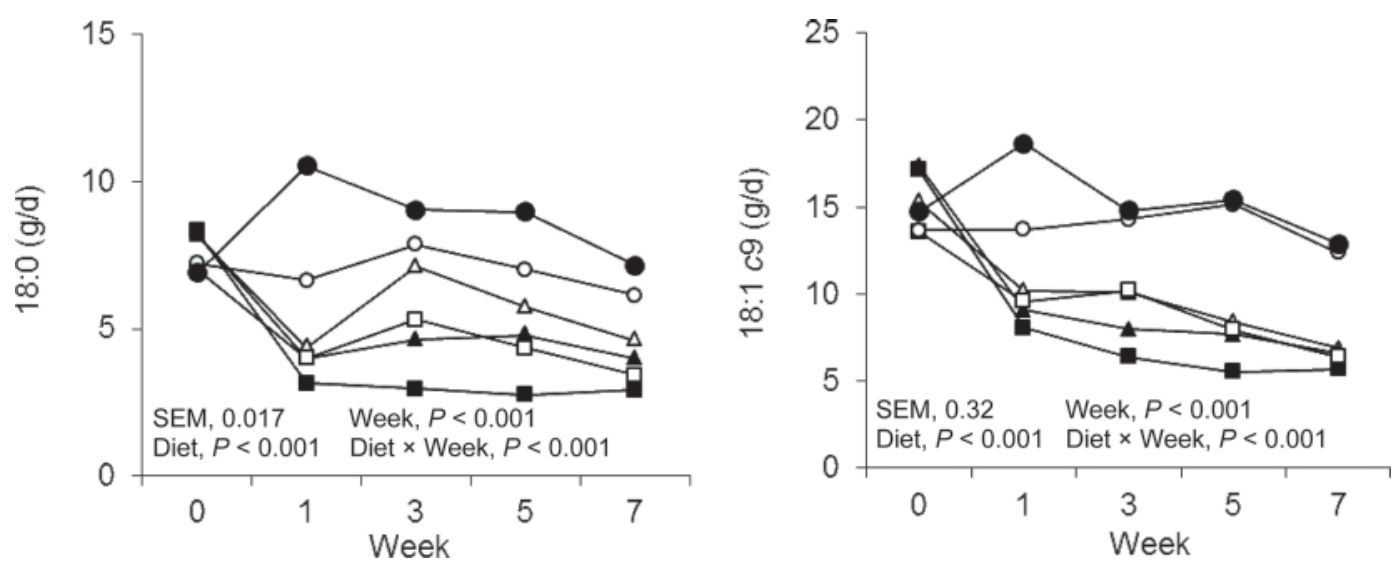

Figure 2. Evolution of the daily excretion of stearic acid (18:0) and oleic acid (18:1 c9) with the milk as affected by diet. $\Delta$, control; $\mathbf{\Lambda}$, lentil straw; $\square$, Atriplex leaves; $\mathbf{\square}$ olive leaves; $\bigcirc$, olive cake; $\bullet$, tomato pomace. $c=$ cis.

\section{DISCUSSION}

As intended by the isoenergetic and isonitrogenous formulation of the diets, differences in performance were not very large. The comparably low ECM yield and weight gain with progressing lactation when feeding olive leaves and olive cake indicated that ME content may have been slightly over-estimated in the preceding digestibility experiments (Abbeddou et al., 2011a,b). It seems that adverse factors like the high acid detergent lignin:NDF ratio (olive leaf, olive cake, and tomato pomace diets), the relatively high content of phenols (olive leaf diet), and the high EE content (olive cake and tomato pomace diet) were more detrimental in lactating sheep with a higher requirement than in juvenile sheep approaching adulthood. Feeding the test feeds to small ruminants in other studies resulted in a decrease (olive cake; Molina-Alcaide et al., 2010), an unchanged (ammonia-treated olive leaves; Fegeros et al., 1995; tomato pomace; Romano et al., 2010), or even an increased milk yield (olive cake; Chiofalo et al., 2004). This discrepancy in results is likely related to the attempt and accuracy achieved in balancing for energy and nutrients needed to cover requirements of the respective animal species and breeds used.

Effects of the different diets on gross composition of milk were also limited in extent. Only the 2 diets with relatively high EE content were able to maintain the same milk fat content as that of the control, whereas milk protein contents tended to be lower. It is known that lipid supplementation in dairy sheep may increase milk fat and, at the same time, decrease protein content (Gómez-Cortés et al., 2008) as a consequence of lower rumen microbial protein synthesis. The comparatively low milk fat content, found with all test forages and especially with lentil straw, despite the fact that the latter was even more fibrous than the control diet, seems puzzling at first glance. However, the high prevalence of total 18:1 trans FA and especially 18:1 t10 in milk fat was obviously associated with a certain inhibition of milk fat synthesis (Bauman and Griinari, 2003; GómezCortés et al., 2008).

\section{Antiradical Activity}

A high antioxidative potential of human food is desired to reinforce the natural defense system against forming free radicals and initiating detrimental oxidative events in the metabolism (Parr and Bolwell, 2000). The main antioxidative compounds in milk are enzymes, lactoferrin, vitamins $\mathrm{C}$ and $\mathrm{E}$, carotenoids (Nozière et al., 2006), and, to a certain extent, phenolic compounds (O'Connell and Fox, 2001). To test their efficiency, many in vitro and in vivo tests have been developed of which the simple free radical DPPH scavenging activity test has been used widely (Liu et al., 2005). Milk from the Atriplex leaf diet showed the highest antiradical activity, followed by diets containing tomato pomace, olive cake, and lentil straw. These diets have different potential active secondary metabolites like lycopene in tomato pomace and phenols in olive cake and Atriplex leaves, and it can be assumed that a transfer of some of these metabolites from feed to milk occurred. According to O'Connell and Fox (2001), phenolic compounds can be found in considerable amounts in ruminant milk, of which the majority originates from feed. It has to be stated that by using methanol as the solvent for the DPPH, polar active compounds like phenols would be the only reactants. Other nonpolar constituents might have been underestimated in their importance. Unexpectedly, the test diet with the highest content of total phenols (olive leaves) led to the lowest antiradical activity of the milk. However, with this diet, milk fat also was highest in 18:3 $c 9, c 12, c 15$ and total PUFA (i.e., FA 


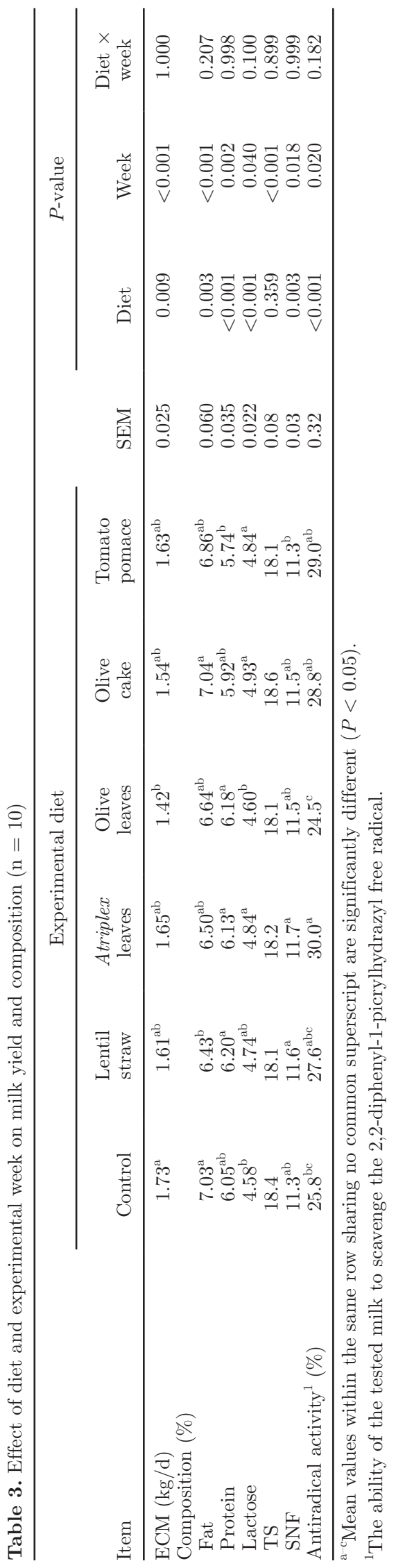

with a high inclination to be oxidized). Therefore, part of the antiradical active agents might have immediately been spent in this case.

\section{Important Fatty Acids and Groups of Fatty Acids in Milk Fat}

Short- and Medium-Chain Fatty Acids. The SCFA and MCFA in milk are mainly synthesized de novo (almost all 4:0 to 14:0 and more than $50 \%$ of 16:0). The de novo synthesis process can be inhibited partly by long-chain FA (from diet or body fat mobilization) and by trans FA (especially 18:1 t10 and 18:2 t10,c12) originating from hydrogenated dietary fat or CLA supplements. The latter are also products of ruminal biohydrogenation (Bauman and Griinari, 2003; Chilliard et al., 2007), but typically are less prevalent than 18:1 t11 and 18:2 $c 9, t 11$, especially in grass- or haybased diets (Leiber et al., 2005). In the present study, SCFA and MCFA levels did not seem to coincide with the ratio of 18:1 $t 10$ to 18:1 $t 11$, though. As expected, the olive cake and tomato pomace diets, containing the most EE and long-chain FA, effectively decreased both SCFA and MCFA contents in milk. Lentil straw, rich in 18:2 $c 9, c 12$ was far less efficient, but 16:0 content in milk fat also decreased to some extent. Contrary to the present results, Tsiplakou and Zervas (2008) found lower contents of SCFA and MCFA in the milk fat of olive leaf-fed ewes. In general, it cannot be totally excluded that shifts in SCFA and MCFA were at least partly the result of shifts in other FA in milk fat.

Oleic Acid and Stearic Acid. Milk 18:1 c9 is mostly generated by mammary $\Delta^{9}$-desaturation of stearic acid (18:0) but can also be transferred from feed to milk to a certain extent (Chilliard et al., 2007). Following the Mediterranean diet health claim, 18:1 $c 9$ has gained attention (Chilliard et al., 2007). Two of the diets resulted in an almost 2-fold 18:1 $c 9$ proportion in milk fat compared with all other diets. In the case of the olive cake diet this can be explained by the high dietary 18:1 $c 9$ level, probably combined with slow ruminal biohydrogenation (Chiofalo et al., 2004). In the case of the tomato pomace, which was not especially rich in 18:1 $c 9$, it can be assumed that 18:0 accumulated in the mammary gland, leading to correspondingly more 18:1 $c 9$, resulting from an unchanged desaturation rate. Indeed, the tomato pomace diet contained much more 18:0 than the other diets except that with olive cake, and another important source of the 18:0 arriving at the mammary gland likely was biohydrogenation of the ample available dietary 18:2 $c 9, c 12$, the transfer of which from feed to milk was lowest with this diet.

Stearic acid in milk has 2 main origins: intake and complete ruminal biohydrogenation of 18-unsaturated 
Table 4. Effect of diet and experimental week on the proportions of fatty acids in milk fat (\% of total fatty acid methyl esters; $\mathrm{n}=10$ )

\begin{tabular}{|c|c|c|c|c|c|c|c|c|c|c|}
\hline Item $^{1}$ & \multicolumn{6}{|c|}{ Experimental diet } & SEM & \multicolumn{3}{|c|}{$P$-value } \\
\hline 18:0 & $7.2^{\mathrm{c}}$ & $6.7^{\mathrm{cd}}$ & $6.2^{\mathrm{d}}$ & $4.7^{\mathrm{e}}$ & $10.0^{\mathrm{b}}$ & $12.4^{\mathrm{a}}$ & 0.182 & $<0.001$ & 0.032 & 0.005 \\
\hline $18: 1 c 9$ & $11.8^{\mathrm{b}}$ & $12.2^{\mathrm{b}}$ & $12.3^{\mathrm{b}}$ & $10.3^{\mathrm{c}}$ & $20.4^{\mathrm{a}}$ & $21.3^{\mathrm{a}}$ & 0.30 & $<0.001$ & $<0.001$ & 0.066 \\
\hline Total 18:1 $\mathrm{cis}^{2}$ & $12.7^{\mathrm{b}}$ & $13.4^{\mathrm{b}}$ & $13.3^{\mathrm{b}}$ & $11.3^{\mathrm{c}}$ & $21.7^{\mathrm{a}}$ & $23.0^{\mathrm{a}}$ & 0.317 & $<0.001$ & $<0.001$ & 0.086 \\
\hline $18: 2 c 9, c 12$ & $3.16^{\mathrm{a}}$ & $3.43^{\mathrm{a}}$ & $3.25^{\mathrm{a}}$ & $3.34^{\mathrm{a}}$ & $2.53^{\mathrm{c}}$ & $2.83^{\mathrm{b}}$ & 0.038 & $<0.001$ & $<0.001$ & 0.277 \\
\hline $18: 2 c 9, t 11$ & $0.349^{\mathrm{c}}$ & $0.507^{\mathrm{ab}}$ & $0.429^{\mathrm{bc}}$ & $0.580^{\mathrm{a}}$ & $0.364^{\mathrm{c}}$ & $0.616^{\mathrm{a}}$ & 0.0131 & $<0.001$ & 0.011 & $<0.001$ \\
\hline $18: 2 \mathrm{c} 9, \mathrm{t} 12$ & $0.066^{\mathrm{b}}$ & $0.075^{\mathrm{b}}$ & $0.066^{\mathrm{b}}$ & $0.068^{\mathrm{b}}$ & $0.070^{\mathrm{b}}$ & $0.117^{\mathrm{a}}$ & 0.0017 & $<0.001$ & $<0.001$ & 0.357 \\
\hline $18: 2 t 11, c 15+t 9, c 12$ & $0.072^{\mathrm{d}}$ & $0.084^{\mathrm{bcd}}$ & $0.089^{\mathrm{bc}}$ & $0.119^{\mathrm{a}}$ & $0.077^{\mathrm{cd}}$ & $0.082^{\text {cd }}$ & 0.0018 & $<0.001$ & 0.315 & 0.146 \\
\hline Total CLA ${ }^{2}$ & $0.431^{\mathrm{c}}$ & $0.603^{\mathrm{ab}}$ & $0.515^{\mathrm{bc}}$ & $0.671^{\mathrm{a}}$ & $0.443^{\mathrm{c}}$ & $0.686^{\mathrm{a}}$ & 0.0134 & $<0.001$ & 0.005 & $<0.001$ \\
\hline $18: 3 c 9, c 12, c 15$ & $0.141^{\mathrm{c}}$ & $0.253^{\mathrm{b}}$ & $0.280^{\mathrm{b}}$ & $0.419^{\mathrm{a}}$ & $0.133^{\mathrm{c}}$ & $0.165^{\mathrm{c}}$ & 0.0071 & $<0.001$ & $<0.001$ & $<0.001$ \\
\hline n-6:n-3 ratio $^{3}$ & $9.57^{\mathrm{a}}$ & $8.12^{\mathrm{b}}$ & $7.10^{\mathrm{c}}$ & $5.82^{\mathrm{d}}$ & $8.51^{\mathrm{b}}$ & $10.48^{\mathrm{a}}$ & 0.163 & $<0.001$ & $<0.001$ & $<0.001$ \\
\hline SCFA & $17.4^{\mathrm{b}}$ & $18.1^{\mathrm{ab}}$ & $18.0^{\mathrm{ab}}$ & $18.8^{\mathrm{a}}$ & $14.0^{\mathrm{c}}$ & $11.9^{\mathrm{d}}$ & 0.19 & $<0.001$ & $<0.001$ & 0.109 \\
\hline MCFA & $53.8^{\mathrm{a}}$ & $51.3^{\mathrm{b}}$ & $53.3^{\mathrm{a}}$ & $54.8^{\mathrm{a}}$ & $46.0^{\mathrm{c}}$ & $42.8^{\mathrm{d}}$ & 0.34 & $<0.001$ & 0.649 & 0.059 \\
\hline SFA & $77.9^{\mathrm{a}}$ & $75.5^{\mathrm{b}}$ & $76.9^{\mathrm{ab}}$ & $77.3^{\mathrm{ab}}$ & $69.6^{\mathrm{c}}$ & $66.2^{\mathrm{d}}$ & 0.35 & $<0.001$ & 0.055 & 0.001 \\
\hline MUFA & $16.9^{\mathrm{d}}$ & $18.7^{\mathrm{c}}$ & $17.5^{\mathrm{cd}}$ & $16.7^{\mathrm{d}}$ & $26.0^{\mathrm{b}}$ & $28.4^{\mathrm{a}}$ & 0.32 & $<0.001$ & 0.242 & 0.180 \\
\hline PUFA & $5.13^{\mathrm{c}}$ & $5.76^{\mathrm{ab}}$ & $5.50^{\mathrm{bc}}$ & $5.94^{\mathrm{a}}$ & $4.44^{\mathrm{d}}$ & $5.41^{\mathrm{c}}$ & 0.053 & $<0.001$ & $<0.001$ & 0.264 \\
\hline
\end{tabular}

${ }^{\mathrm{a} e}$ Mean values within the same row sharing no common superscript are significantly different $(P<0.05)$.

${ }^{1} c=$ cis; $t=$ trans; CLA $=$ conjugated linoleic acids; SCFA = short-chain fatty acids, 4:0 to 11:0; MCFA = medium-chain fatty acids, $12: 0$ to 16:1; SFA = saturated fatty acids; MUFA $=$ monounsaturated fatty acids; PUFA $=$ polyunsaturated fatty acids.

${ }^{2}$ Total 18:1 $c i s=$ sum of 18:1 $c 9$ and 18:1 $c 11$ to $c 14$; total 18:1 trans $=$ sum of 18:1 t4 to $t 12$; total CLA = sum of 18:2 $c 9, t 11,18: 2 c 9, c 11$, and $18: 2$ t9, $t 11$.

${ }^{3}$ Unit without dimension.

FA (Chilliard et al., 2007; Gómez-Cortés et al., 2008). Accordingly, its excretion with milk was far higher than the amount consumed. This FA was especially enriched in the milk fat of diets with olive cake (rich in dietary 18:1 $c 9$ ) and tomato pomace (rich in dietary 18:2 $c 9, c 12$ ). For olive cake, this was different than the results of Chiofalo et al. (2004). According to GómezCortés et al. (2008), the biohydrogenation of 18:1 $c 9$ would generate 18:0, together with a variety of 18:1 trans, with the exception of $18: 1 t 11$, which is consistent with the present observations of a low transfer rate of C18:1 $c 9$ from diet to milk when feeding olive cake. n-3 Fatty Acids. All tested forages increased proportions of 18:3 $c 9, c 12, c 15$ and, less clearly, 20:5 $c 5, c 8, c 11, c 14, c 17, \quad 22: 5 \quad c 7, c 10, c 13, c 16, c 19$ and $22: 6$ $c 4, c 7, c 10, c 13, c 16, c 19$ in milk fat compared with the control and diets with olive cake and tomato pomace. This indicates that the increase was a consequence of decreased biohydrogenation of 18:3 $c 9, c 12, c 15$ and not that of extra intake of this FA or EE. When evaluated across all diets, the proportion of dietary 18:3 $c 9, c 12, c 15$ recovered in milk was clearly decreasing with increasing intake, as has been found before (e.g., Kälber et al., 2011). Its content in milk fat even decreased when $6 \%$

Table 5. Effect of diet and experimental week on the recovery rate of selected fatty acids (FA; $\mathrm{g}$ of FA excreted in milk/g of FA intake; $\mathrm{n}=10$ )

\begin{tabular}{|c|c|c|c|c|c|c|c|c|c|c|}
\hline Item $^{1}$ & \multicolumn{6}{|c|}{ Experimental diet } & SEM & \multicolumn{3}{|c|}{$P$-value } \\
\hline $18: 2 c 9, c 12$ & $0.097^{\mathrm{a}}$ & $0.072^{\mathrm{b}}$ & $0.103^{\mathrm{a}}$ & $0.094^{\mathrm{a}}$ & $0.089^{\mathrm{ab}}$ & $0.031^{\mathrm{c}}$ & 0.0024 & $<0.001$ & $<0.001$ & 0.625 \\
\hline $18: 1 c 9$ & $0.935^{\mathrm{a}}$ & $0.644^{\mathrm{b}}$ & $0.953^{\mathrm{a}}$ & $0.688^{\mathrm{b}}$ & $0.411^{c}$ & $0.641^{\mathrm{b}}$ & 0.0206 & $<0.001$ & $<0.001$ & 0.463 \\
\hline $18: 0$ & $4.53^{\mathrm{a}}$ & $2.97^{\mathrm{b}}$ & $4.69^{\mathrm{a}}$ & $3.10^{\mathrm{b}}$ & $2.42^{\mathrm{bc}}$ & $1.77^{\mathrm{c}}$ & 0.107 & $<0.001$ & 0.001 & 0.190 \\
\hline
\end{tabular}

${ }^{\mathrm{a}-\mathrm{d}}$ Mean values within the same row sharing no common superscript are significantly different $(P<0.05)$.

${ }^{1} c=$ cis. 
olive oil was added to the diet (Gómez-Cortés et al., 2008). As 18:3 $c 9, c 12, c 15$ is the precursor of the very long-chain n-3 FA (Chilliard et al., 2007), its increase in milk fat with the olive leaf diet was associated with these FA. Partially inhibited ruminal biohydrogenation due to phenols was described before for condensed tannins (Khiaosa-Ard et al., 2009), but this does not explain the present finding, as this inhibition did not encompass 18:3 $c 9, c 12, c 15$ biohydrogenation itself.

Biohydrogenation Intermediates. The ruminal biohydrogenation of 18:2 $c 9, c 12$ and 18:3 $c 9, c 12, c 15$ and the isomerization of $18: 1 c 9$ result in a series of intermediates, whereof 2 specific isomers, 18:1 $t 10$ and 18:1 $t 11$, are of particular interest (Gómez-Cortés et al., 2008; Khiaosa-Ard et al., 2010). The 18:1 t11 isomer is formed from both 18:2 $c 9, c 12$ and 18:3 $c 9 c 12 c 15$, whereas 18:1 t10 originates from 18:2 $c 9, c 12$ only (Chilliard et al., 2007). Gómez-Cortés et al. (2008) pointed out that 18:1 t10 is primarily produced from the isomerization of 18:1 $c 9$.

When feeding the olive leaf diet, containing $9.3 \%$ 18:3 $c 9, c 12, c 15$ of total dietary FAME, this FA was probably the main substrate for biohydrogenation, as this resulted in an increase in 18:1 $t 11$, consistent with results of Tsiplakou and Zervas (2008), and a clear increase in 18:2 t11,c15 as well (Chilliard et al., 2007). In addition, 18:2 $c 9, t 11$ was elevated. This CLA isomer, although being an intermediate in ruminal biohydrogenation of $18: 2 c 9, c 12$, is mainly synthesized by $\Delta^{9}$-desaturation of $18: 1 t 11$ in the mammary gland (Griinari et al., 2000; Chilliard et al., 2007). One source of condensed tannins tested by Khiaosa-Ard et al. (2009) was found to inhibit one important step in biohydrogenation and, therefore, resulted in 18:1 t11 accumulation and 18:0 depletion. This was similar to the present findings. Among the test feeds, olive leaves were highest in total phenols and total tannins, though not in condensed tannins, suggesting that a comparable mechanism influenced microbial biohydrogenation. Still a proportionately higher increase occurred in 18:1 $t 10$ than in 18:1 t11 with olive leaves, although its main precursor, 18:2 $c 9, c 12$, was low in the dietary lipids. As the olive leaf diet in our study was higher in non-NDF carbohydrates than the control diet, a certain decrease in rumen fluid $\mathrm{pH}$ could have occurred, which is known to facilitate 18:1 t10 formation (Chilliard et al., 2007). This may have been caused by a shift from Butyrivibrio fibrisolvens, which isomerizes the $c 12$ bond to $t 11$, to Megasphaera elsdenii, which isomerizes the $c 9$ bond to t10 (Kramer et al., 2004).

In the case of tomato pomace and lentil straw, where the most abundant FA in the diet was 18:2 $c 9, c 12(36.5$ and $35.1 \%$ of total FAME in the diet, respectively), an increase in 18:1 t11 was also found. According to
Bauman et al. (1999), high levels of 18:2 $c 9, c 12$ would inhibit further biohydrogenation of the intermediate 18:1 $t 11$, resulting in its accumulation as the major end product instead of 18:0. With lentil straw, 18:1 t10 accumulation in milk fat was the highest of all diets but, different from the olive leaves, probably because enough substrate was available $(18: 2 c 9, c 12)$.

\section{CONCLUSIONS}

Several forages and agro-industrial byproducts, typical for dry areas, offer the opportunity to improve milk fat properties. An added value may be obtained by enhancing the proportion of FA with potential health benefits, namely 18:1 $c 9$ (with olive cake and tomato pomace), n-3 PUFA, and 18:2 $c 9, t 11$ (with olive leaves and lentil straw), as well as the antioxidative stability of the milk (with saltbush leaves). As effects and modes of action largely differed, combinations of these feeds might be complementary and, thus, may improve milk fat properties in several aspects at once.

\section{ACKNOWLEDGMENTS}

The authors acknowledge the financial support of the Swiss Development Cooperation, Berne, through the North-South Center, ETH Zurich, Switzerland. The authors thank the collaborators at the International Center for Agricultural Research in the Dry Areas (ICARDA, Aleppo, Syria), Luis Iñiguez, a senior small ruminant scientist, for developing the project, Safouh Rihawi, animal nutritionist, for his help in the diet formulations, Monika Zaklouta, a research associate, for coordinating the study, and all technicians and workers at ICARDA who took part in the animal experiments, the laboratory analyses, and the animal health care. Special thanks go to the general staff at the Small Ruminant Unit at ICARDA, Ahmad Sawas, Mohammed Haylani, and Gassan Jesry and their teams.

\section{REFERENCES}

Abbeddou, S., S. Rihawi, H. D. Hess, L. Iñiguez, A. C. Mayer, and M. Kreuzer. 2011a. Nutritional composition of lentil straw, vetch hay, olive leaves and saltbush leaves, and their digestibility as measured in fat-tailed sheep. Small Rumin. Res. 96:126-135.

Abbeddou, S., S. Rihawi, L. Iñiguez, M. Zaklouta, H. D. Hess, and M. Kreuzer. 2011b. Ruminal degradability, digestibility, energy content, and influence on nitrogen and mineral turnover of various Mediterranean by-products in fat-tailed Awassi sheep. Anim. Feed Sci. Technol. 163:99-110.

ALP (Agroscope Liebefeld-Posieux). 2008. Feeding recommendations and nutrient tables (in German). Online version. ALP, Posieux, Switzerland. Accessed on November 25, 2010. http://www.alp.admin.ch/dokumentation/00611/00631/index.html?lang=de.

AOAC. 1997. Official Methods of Analysis. Association of Official Analytical Chemists, Arlington, VA.

Bauman, D. E., L. H. Baumgard, B. A. Corl, and J. M. Griinari. 1999. Biosynthesis of conjugated linoleic acid in ruminants. J. Anim. Sci. 77 (E-suppl.):1-15. 
Bauman, D. E., and J. M. Griinari. 2003. Nutritional regulation of milk fat synthesis. Annu. Rev. Nutr. 23:203-227.

Burdge, G. C. 2006. Metabolism of $\alpha$-linolenic acid in humans. Prostaglandins Leukot. Essent. Fatty Acids 75:161-168.

Chilliard, Y., F. Glasser, A. Ferlay, L. Bernard, J. Rouel, and M Doreau. 2007. Diet, rumen biohydrogenation and nutritional quality of cow and goat milk fat. Eur. J. Lipid Sci. Technol. 109:828855 .

Chiofalo, B., L. Liotta, A. Zumbo, and V. Chiofalo. 2004. Administration of olive cake for ewe feeding: Effect on milk yield and composition. Small Rumin. Res. 55:169-176.

Collomb, M., and T. Bühler. 2000. Analyse de la composition en acides gras de la graisse de lait. I. Optimisation et validation d'une méthode générale à haute résolution. Mitt. Lebensmittelunters. Hyg. 91:306-332.

Council for International Organizations of Medical Sciences. 2010 International guiding principles for biomedical research involving animals. Accessed on Nov. 11, 2010. http://www.anim.med.kyotou.ac.jp/arcku/AnimExp/IGP.pdf.

Fegeros, K., G. Zervas, F. Apsokardos, J. Vastardis, and E. Apostolaki. 1995. Nutritive evaluation of ammonia-treated olive tree leaves for lactating sheep. Small Rumin. Res. 17:9-15.

Gómez-Cortés, P., P. Frutos, A. R. Mantecón, M. Juárez, M. A. de la Fuente, and G. Hervás. 2008. Addition of olive oil to dairy ewe diets: Effect on milk fatty acid profile and animal performance. J. Dairy Sci. 91:3119-3127.

Goudjil, H., J. Fontecha, P. Luna, M. A. de la Fuente, L. Alonso, and M. Juárez. 2004. Quantitative characterization of unsaturated and trans fatty acids in ewe's milk fat. Lait 84:473-482.

Griinari, J. M., B. A. Corl, S. H. Lacy, P. Y. Chouinard, K. V. V. Nurmela, and D. E. Bauman. 2000. Conjugated linoleic acid is synthesized endogenously in lactating dairy cows by $\Delta^{9}$-desaturase. J. Nutr. 130:2285-2291.

IUPAC (International Union of Pure and Applied Chemistry). 1987. Standard Methods for the Analysis of Oils, Fats and Derivates. 7th ed. Blackwell Scientific Publications, Oxford, UK.

Kälber, T., J. S. Meier, M. Kreuzer, and F. Leiber. 2011. Flowering catch crops used as forage plants for dairy cows: Influence on fatty acids and tocopherols in milk. J. Dairy Sci. 94:1477-1489.

Khiaosa-Ard, R., S. F. Bryner, M. R. L. Scheeder, H.-R. Wettstein, F. Leiber, M. Kreuzer, and C. R. Soliva. 2009. Evidence for the inhibition of the terminal step of ruminal $\alpha$-linolenic acid biohydrogenation by condensed tannins. J. Dairy Sci. 92:177-188.

Khiaosa-Ard, R., F. Klevenhusen, C. R. Soliva, M. Kreuzer, and F. Leiber. 2010. Transfer of linoleic and linolenic acid from feed to milk in cows fed isoenergetic diets differing in proportion and origin of concentrates and roughages. J. Dairy Res. 77:331-336.

Kramer, J. K. G., C. Cruz-Hernandez, Z. Deng, J. Zhou, G. Jahreis, and M. E. R. Dugan. 2004. Analysis of conjugated linoleic acid and trans 18:1 isomers in synthetic and animal products. Am. J. Clin. Nutr. 79(Suppl.):1137S-1145S.

Kromhout, D., E. J. Giltay, and J. M. Geleijnse. 2010. n-3 fatty acids and cardiovascular events after myocardial infarction. N. Engl. J. Med. 363:2015-2026

Lanzani, A., P. Bondioli, L. Folegatti, E. Fedeli, V. Bontempo, V. Chiofalo, G. Panichi, and V. Dell'Orto. 1993. Impiego di sanse di olive integrate nell'alimentazione della pecora da latte: Effetti sulle produzioni quali-quantitative di latte. Rivista Italiana delle Sostanze Grasse 70:375-383.

Leiber, F., M. Kreuzer, D. Nigg, H.-R. Wettstein, and M. R. L. Scheeder. 2005. A study on the causes for the elevated n-3 fatty acids in cows' milk of alpine origin. Lipids 40:191-202.
Lindmark-Månsson, H., and B. Åkesson. 2000. Antioxidative factors in milk. Br. J. Nutr. 84(Suppl. 1):S103-S110.

Liu, J.-R., M.-J. Chen, and C.-W. Lin. 2005. Antimutagenic and antioxidant properties of milk-kefir and soymilk-kefir. J. Agric. Food Chem. 53:2467-2474

Lourenço, M., G. Van Ranst, B. Vlaeminck, S. De Smet, and V. Fievez. 2008. Influence of different dietary forages on the fatty acid composition of rumen digesta as well as ruminant meat and milk. Anim. Feed Sci. Technol. 145:418-437.

Makkar, H. P. S. 2003a. Effects and fate of tannins in ruminant animals, adaptation to tannins, and strategies to overcome detrimental effects of feeding tannin-rich feeds. Small Rumin. Res. 49:241-256.

Makkar, H. P. S. 2003b. Quantification of Tannins in Tree and Shrub Foliage, a Laboratory Manual. Kluwer Academic Publishers, Dordrecht, the Netherlands.

Martin, B., V. Fedele, A. Ferlay, P. Grolier, E. Rock, D. Gruffat, and Y. Chilliard. 2004. Effects of grass-based diets on the content of micronutrients and fatty acids in bovine and caprine dairy products. Pages 876-886 in Proc. 20th General Meeting Eur. Grassl Fed., Luzern, Switzerland. A. Lúscher, B. Jeangros, W. Kessler, O. Huguenin, M. Lobsiger, N. Millar, and D. Suter, ed.

Molina-Alcaide, E., E. Y. Morales-García, A. I. Martín-García, H. Ben Salem, A. Nefzaoui, and M. R. Sanz-Sampelayo. 2010. Effects of partial replacement of concentrate with feed blocks on nutrient utilization, microbial $\mathrm{N}$ flow, and milk yield and composition in goats. J. Dairy Sci. 93:2076-2087.

Molkentin, J., and D. Precht. 2000. Validation of a gas-chromatographic method for the determination of milk fat contents in mixed fats by butyric acid analysis. Eur. J. Lipid Sci. Technol. 102:194-201.

Nozière, P., B. Graulet, A. Lucas, B. Martin, P. Grolier, and M. Doreau. 2006. Carotenoids for ruminants: From forages to dairy products. Anim. Feed Sci. Technol. 131:418-450.

O'Connell, J. E., and P. F. Fox. 2001. Significance and applications of phenolic compounds in the production and quality of milk and dairy products: A review. Int. Dairy J. 11:103-120.

Parr, A. J., and G. P. Bolwell. 2000. Phenols in the plant and in man. The potential for possible nutritional enhancement of the diet by modifying the phenols content or profile. J. Sci. Food Agric. 80:985-1012.

Porter, L. J., L. N. Hrstich, and B. G. Chan. 1986. The conversion of procyanidins and prodelphinidins to cyanidin and delphinidin. Phytochemistry 25:223-230.

Romano, R., F. Masucci, A. Giordano, S. S. Musso, D. Naviglio, and A. Santini. 2010. Effect of tomato by-products in the diet of Comisana sheep on composition and conjugated linoleic acid content of milk fat. Int. Dairy J. 20:858-862.

SAS Institute. 2009. SAS/STAT User's Guide, Version 9.2. SAS Institute, Cary, NC

Tsiplakou, E., and G. Zervas. 2008. The effect of dietary inclusion of olive tree leaves and grape marc on the content of conjugated linoleic acid and vaccenic acid in the milk of dairy sheep and goats. J. Dairy Res. 75:270-278.

Van Soest, P. J., J. B. Robertson, and B. A. Lewis. 1991. Methods for dietary fiber, neutral detergent fiber, and nonstarch polysaccharides in relation to animal nutrition. J. Dairy Sci. 74:3583-3597.

Vasta, V., A. Nudda, A. Cannas, M. Lanza, and A. Priolo. 2008. Alternative feed resources and their effects on the quality of meat and milk from small ruminants. Anim. Feed Sci. Technol. 147:223246. 